\title{
FITNESS EFFECTS FROM EGG TO REPRODUCTION: BRIDGING THE LIFE HISTORY TRANSITION
}

\author{
Marjan De Block ${ }^{1}$ And Robby Stoks ${ }^{2,3}$ \\ ${ }^{1}$ Department of Biology, Evolutionary Biology Group, University of Antwerp, Groenenborgerlaan 171, \\ B-2020 Antwerp, Belgium \\ ${ }^{2}$ Laboratory of Aquatic Ecology, University of Leuven, Ch. De Bériotstraat 32, B-3000 Leuven, Belgium
}

\begin{abstract}
Although complex life cycles are widespread, we know little about how constraints in the larval stage influence adult fitness. Most models assume a tight coupling of larval conditions and adult fitness through size and timing of the life history transition. However, there are few empirical tests of this assumption. We combined an experimental manipulation of larval environment with a subsequent study of adult fitness, measured as lifetime mating success. Individuals of the damselfly Lestes viridis were followed from the egg stage to adult reproduction and death. Under time constraints, emergence occurred earlier, but in late-hatched larvae, this did not result in a lower size. Under nutritional constraints, emergence occurred later, and size was reduced. Variation in survival to maturity was better explained by larval constraints than by emergence traits, whereas both larval constraints and emergence traits explained variation in lifetime mating success. Sexes reacted differently to larval constraints, and the coupling of larval constraints to adult fitness also was sex specific. Our results indicate that larval constraints do not necessarily carry over to adult fitness through size and timing of transition, and that carryover effects may be sex specific. This may explain the existence of hidden costs that become visible after maturation and may explain part of the unexplained variation in selection studies on adults.
\end{abstract}

Key words: adult fitness; carryover effects; complex life cycle; damselflies; food stress; hidden costs; larval constraints; Lestes viridis; optimality models; sex-specific response; time constraints.

\section{INTRODUCTION}

Many animals have a complex life cycle with discrete larval and adult stages living in two distinct habitats (Moran 1994). An early transition and a large size at the transition between the larval and adult stage typically increase fitness in the adult stage. However, a short larval stage comes at the cost of a reduced period of growth and, therefore, often a reduced size at transition. Hence, a trade-off exists between size and the timing of the life history transition. The optimal balance between size and timing will depend on several ecological constraints in the larval stage, such as time constraints (e.g., onset of winter, pond drying) and nutritional constraints (Nylin and Gotthard 1998). For example, under time constraints, an early transition will probably be more essential to fitness than size at the transition. Our understanding of the effects of such constraints on life history is driven by optimality models, which have guided many empirical studies testing their predictions (overview in Day and Rowe 2002). These models typically consider only size and timing of the life history transition, because these are assumed to tightly couple constraints during the larval stage with

Manuscript received 15 January 2004; revised 11 June 2004; accepted 15 July 2004. Corresponding Editor: A. Sih.

${ }^{3}$ Corresponding author.

E-mail: robby.stoks@bio.kuleuven.ac.be adult fitness. However, two issues may invalidate model predictions based on the presumed role of size and timing of transition in bridging the gap between larval constraints and adult fitness.

First, larval constraints may affect adult fitness not only through the life history variables at the transition that are included in the optimality models, but also through other variables. For example, fat content, which may be reduced irrespective of size under a nutritional constraint, may also determine mating success (Plaistow and Siva-Jothy 1996, 1999). If other traits at transition exist that are affected by larval constraints and are important for adult fitness, then it is crucial for current models that their variation is captured by size and the timing of transition. If not, these traits very likely are independent targets of selection and should be included in optimality models to obtain realistic predictions. Ignoring them will underestimate the costs of constraints imposed during larval life. Intriguingly, empirical support for the key assumption that size and timing of transition completely mediate the transition of constraints experienced during the larval stage into adult fitness is scarce because most empirical studies have size and timing of transition, and not adult fitness, as end points.

Second, because the relationship between these two life history variables and adult fitness is often unknown for particular species, authors rely on broad general- 
izations, which do not necessarily hold. For example, body size is generally believed to be positively correlated with fitness (Honěk 1993, Sokolovska et al. 2000), but some studies have disagreed with this assumption (Andersson 1994, Thompson and Fincke 2002). In addition, most models (but see, e.g., Crowley 2000) and empirical tests (but see, e.g., Morey and Reznick 2001) fail to acknowledge that the relationship between larval constraints and adult fitness may not be general within a species and may be sex specific. Also, size and the timing of transition may differentially affect fitness components such as early survival and lifetime mating success (e.g., Anholt 1991). Yet most studies that look beyond the life history transition have considered only early fitness measures, such as juvenile growth rate, and survival to the next season. Taken together, there is a need for studies that link larval constraints to sex-specific adult fitness components and evaluate whether the larval constraints indeed only operate through size and timing of the transition (see also Altwegg and Reyer 2003).

Here we present the results of a longitudinal study in which individual damselflies Lestes viridis were observed from egg hatching to adult reproduction and death. We first examined the effects of time and nutritional constraints during the larval stage on life history responses at emergence (i.e., time and size at emergence). We then looked at effects of size and time at emergence on lifetime mating success and its two components, survival to reproductive maturity and lifetime mating success once mature, in both sexes. We addressed time constraints in two ways. Besides manipulating time constraints by imposing different photoperiods (Johansson and Rowe 1999), we also included natural variation in time constraints associated with variation in egg hatching date. This allowed assessment of differential life history plasticity among larvae with a different natural time constraint. Both time constraints and nutritional constraints are relevant in this species. It is obligatory univoltine, winters in the egg stage, and has a short aquatic larval development stage of about three months in spring. After emergence, it takes roughly five weeks to reach reproductive maturity. Adults reproduce from July through October (Jödicke 1997). Within natural populations, there is considerable variation in egg hatching date (6-10 weeks) and in adult emergence date (7-9 weeks) (M. De Block, unpublished data), which creates considerable variation in natural time constraints. Food limitation also is likely in Lestes populations (Pickup et al. 1984, De Block and Stoks 2004).

Based on theoretical and empirical work, we made the following a priori predictions. Under a time constraint, larvae should reduce development time and, if possible, should do so by increasing growth rate to keep size at emergence constant (Abrams et al. 1996). Under a food constraint, larvae will have longer development times, reduced growth rates, and will emerge at a small- er size (Roff 1986). Sex-specific life history responses to larval constraints will generate a smaller male size relative to female size and a more pronounced decrease in development time in males relative to females (Crowley 2000, Crowley and Johansson 2002). This is because, for both sexes, a higher mass at emergence will increase adult fitness (Sokolovska et al. 2000), but this is especially true for females (Crowley and Johansson 2002). Based on current optimality models, we expect that larval constraints will affect adult fitness completely through their effects on size and timing of emergence.

\section{Methods}

\section{Larval rearing experiment}

We obtained eggs from 11 full-sib families from a population in Antwerp, Belgium, in July 2001, closely following the methodology of De Block and Stoks (2003). Lestes viridis deposits eggs under the bark of trees at the waterside; trees with full-sib eggs were collected and kept outside during winter in the garden of the University of Antwerp. Next spring, the natural hatching pattern of the eggs was monitored on a daily basis and freshly hatched larvae were transferred immediately to the laboratory and placed individually in nontransparent plastic cups (diameter $5 \mathrm{~cm}$, height 9 $\mathrm{cm}$ ) filled to a height of $4 \mathrm{~cm}$ with filtered pond water.

Each larva was randomly allocated to one of the four combinations of manipulated time and nutritional constraints. Time constraints were manipulated by rearing larvae in a climate room either at the photoperiod corresponding with the actual date (actual photoperiod) or at the photoperiod that larvae would experience if the eggs had hatched six weeks later (delayed photoperiod). Throughout the experiment, photoperiods were adjusted every 10 days to simulate the natural progress of the light cycle. Because only two climate rooms were available, all larvae of the same photoperiod treatment shared the same climate room at any given time, which may have made experimental units within the same photoperiod treatment more similar to each other than to the ones in the other photoperiod treatment. To minimize potential confounding differences between the two climate rooms, larvae and their respective photoperiod were rotated between climate rooms every 10 days (see Johansson and Rowe 1999). Nutritional constraints were manipulated by feeding larvae six times a week (high food level), or only three times a week (low food level), based on Johansson et al. (2001). Larvae were fed with laboratory-reared brine shrimp nauplii. The number of shrimp fed to a single larva on each feeding occasion was $265 \pm 9$ (mean \pm 1 SE; $n$ $=20$ ). Shrimp died within $\sim 2$ hours after each feeding. From then until the next feeding, damselfly larvae had no food available. When larvae molted into their final larval stage, they were fed two chironomid larvae per feeding occasion to provide them with enough food to 


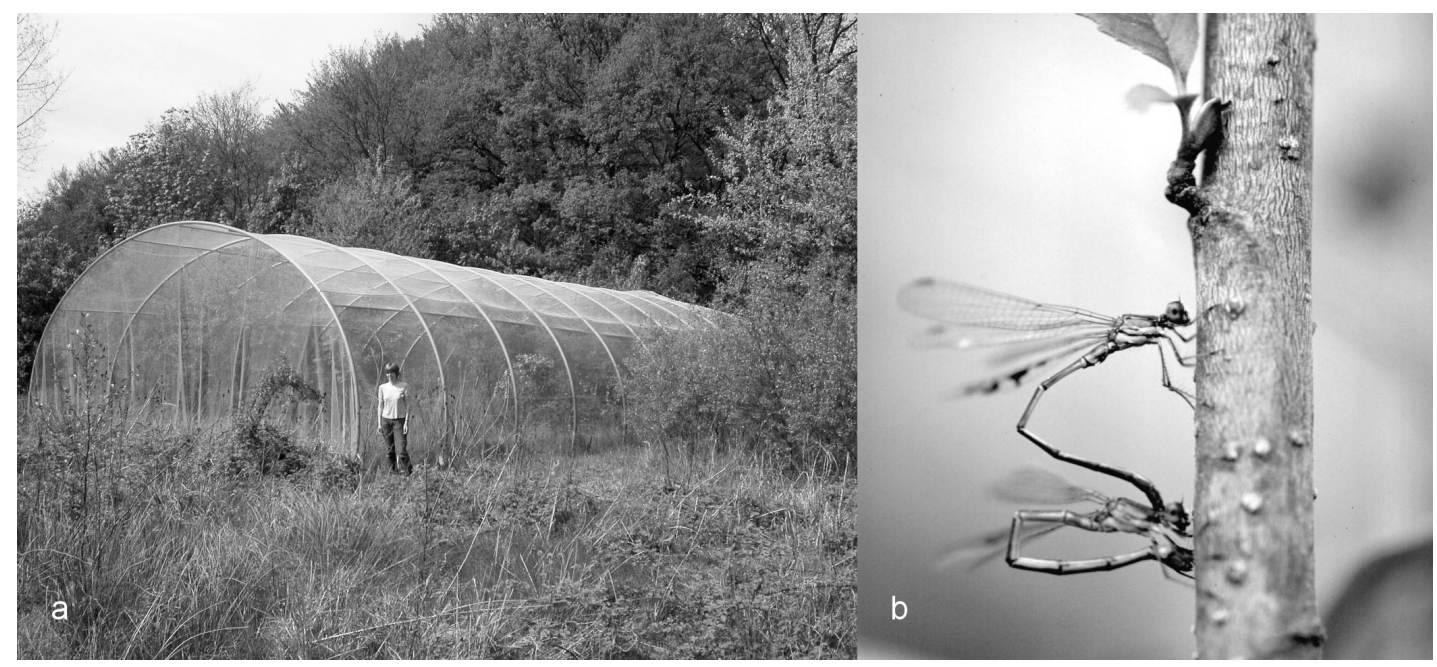

FIG. 1. (a) Outside view of the insectary, and (b) ovipositing pair of Lestes viridis in tandem.

emerge. Temperature in the rooms was held constant at $20^{\circ} \mathrm{C} \pm 1{ }^{\circ} \mathrm{C}$.

Age at emergence (development time) was calculated as the number of days from egg hatching until emergence of the adult. One day after emergence, when the exoskeleton and wings were hardened, mass was determined by weighing the damselflies to the nearest $0.01 \mathrm{mg}$. Growth rate was calculated as $\log _{e}$ (mass) divided by development time (see Johansson and Rowe 1999). Animals were sexed and those that emerged successfully (fully extended wings and abdomen) were individually marked by writing a number on one of the wings with a permanent marker (Staedtler Lumocolor, Staedtler, Germany).

Statistical analyses.-Sex differences in egg hatching date were analyzed with a mixed-model ANOVA. We tested the effects of time constraints (hatching date, photoperiod), nutritional constraints (food level), and sex on the life history variables (age and mass at emergence, and growth rate) in a multivariate analysis framework. This was done by treating life history variables as repeated measures in a mixed-regression model with egg hatching date as a continuous predictor variable in PROC MIXED of SAS 8.02 (Littell et al. 1996, SAS Institute 2000). Family and all interactions with family were included as random variables, but because they were not the focus of the present study, they will not be reported. Egg hatching date and age at emergence were $\log _{e}$-transformed to meet model assumptions. We also performed separate univariate mixed-model ANCOVAs for each life history variable with egg hatching date as a covariate. The effects of egg hatching date, photoperiod, food level, and sex on the probability of successful emergence were analyzed using the GENMOD procedure with logit link and binomial errors in SAS 8.02 (SAS Institute 2000). We initially started with full factorial models and proceeded with stepwise simplification of the models by sequentially removing the highest factor term that was not significant, ending with a minimum adequate model (Crawley 1993, 2002, Verbeke and Molenberghs 1997). Correct degrees of freedom were obtained with the Satterthwaite option (Verbeke and Molenberghs 1997).

\section{Monitoring of adult fitness}

Fitness components were monitored for marked animals released in a large insectary $(10 \times 22 \times 4.5 \mathrm{~m})$ in the garden of the University of Antwerp (Fig. 1a). This insectary included the three natural habitats encountered by L. viridis: a small pond with six small trees for oviposition, a grassy area for foraging, and a wooded area for foraging and roosting. Lestes damselflies behave naturally in this large insectary (Stoks 1999). Ideally, adult fitness should be measured in a completely natural population. However, one cannot then separate death from dispersal to other reproductive sites, which may bias inferences about the link between emergence traits and fitness (Anholt 1990). Furthermore, matings can easily be missed in natural populations with abundant oviposition substrates.

Lifetime mating success, defined as the total number of mates acquired by each individual, was determined and broken into its two components: survival to reproductive maturity and mating success after attaining reproductive maturity. Because the youngest males and females copulated at the age of 28 days, we considered animals that reached this age as having survived to reproductive maturity. Mating success after attaining reproductive maturity was defined as the number of mates acquired by those individuals surviving to reproductive maturity (Anholt 1991). To score these fitness components, we checked the insectary daily from the end of July through mid October for surviving damselflies. When the first animals reached the adult age, the pond portion of the insectary was monitored continuously each day from 10:00 until 18:00 hours, and 
TABLE 1. Set of a priori models of the effects of larval constraints and emergence traits on lifetime mating success of all successfully emerged animals, and its two components: survival to reproductive maturity and mating success once mature.

\begin{tabular}{|c|c|c|c|c|c|c|c|c|c|c|}
\hline \multirow[b]{2}{*}{ Model } & \multirow[b]{2}{*}{$K$} & \multicolumn{3}{|c|}{ Lifetime mating success } & \multicolumn{3}{|c|}{ Survival to maturity } & \multicolumn{3}{|c|}{ Mating success once mature } \\
\hline & & $L$ & $\Delta \mathrm{AIC}$ & $w_{i}$ & $L$ & $\Delta \mathrm{AIC}$ & $w_{i}$ & $L$ & $\Delta \mathrm{AIC}$ & $w_{i}$ \\
\hline \multicolumn{11}{|l|}{ Larval constraints } \\
\hline 1) HD, photo, food & 15 & -595.05 & 31.47 & $<0.001$ & -483.24 & 8.10 & $<0.001$ & -182.04 & 20.78 & $<0.001$ \\
\hline $\begin{array}{l}\text { 2) HD, photo, food, } \\
\text { HD } \times \text { sex, photo } \\
\times \text { sex, food } \times \\
\text { sex }\end{array}$ & 18 & -584.16 & 15.68 & $<0.001$ & -476.19 & 0.00 & 0.786 & -170.72 & 4.13 & 0.016 \\
\hline \multicolumn{11}{|l|}{ Emergence traits } \\
\hline 3) ED, mass & 14 & -598.67 & 36.70 & $<0.001$ & -487.30 & 14.23 & $<0.001$ & -180.13 & 14.96 & $<0.001$ \\
\hline 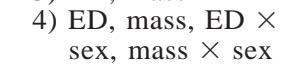 & 16 & -596.55 & 36.45 & $<0.001$ & -485.21 & 14.03 & $<0.001$ & -176.80 & 12.30 & $<0.001$ \\
\hline $\begin{array}{l}\text { 5) } \mathrm{ED}, \text { mass, }(\mathrm{ED})^{2} \text {, } \\
(\text { mass })^{2}, \mathrm{ED} \times \\
\text { mass }\end{array}$ & 17 & -595.62 & 36.59 & $<0.001$ & -486.77 & 19.15 & $<0.001$ & -179.50 & 19.70 & $<0.001$ \\
\hline \multicolumn{11}{|l|}{ Combined model } \\
\hline $\begin{array}{l}\text { 6) HD, photo, food, } \\
\text { ED, mass, HD } \times \\
\text { sex, photo } \times \text { sex, } \\
\text { food } \times \text { sex, ED } \\
\times \text { sex, mass } \times \\
\text { sex }\end{array}$ & 22 & -572.32 & 0.00 & 0.999 & -472.84 & 1.30 & 0.214 & -164.65 & 0.00 & 0.984 \\
\hline
\end{tabular}

Notes: Sex and family are included in all the models but are not mentioned explicitly. Variables that differ among models are explicitly given: hatching date (HD), photoperiod (photo), food level (food), emergence date (ED), and mass at emergence (mass). The number of parameters $(K)$, maximized log-likelihood $(L)$, the difference in Akaike's Information Criterion to the best model $(\triangle \mathrm{AIC})$, and Akaike weights $\left(w_{i}\right)$ are given for each model.

all matings were registered. All copulations observed were followed by oviposition, meaning that lifetime mating success was equal to lifetime number of oviposition bouts for both sexes. We are confident that we observed all matings because, after copulation, males stay connected to females throughout the entire oviposition bout (duration: $1.43 \pm 0.08 \mathrm{~h}$, mean $\pm 1 \mathrm{SE}$, $n=42$; Fig. 1b) and because oviposition only occurred in the six small trees at the pond. Ideally, we should have included lifetime reproductive success (accounting also for clutch size) as a fitness measure, but this was logistically not feasible. In the related Lestes spon$s a$, variation in clutch size per mating, however, was numerically much less important than the variation in lifetime mating success (Stoks 1999; see also Fincke [1988] for another scrambling damselfly).

Statistical analyses.-We focused first on how larval constraints affected lifetime mating success of all animals $(n=1228)$, including those that did not emerge successfully (given a lifetime mating success of zero). Note that in this analysis we could not include emergence traits. The effects of egg hatching date, photoperiod, food level, and sex on lifetime mating success were analyzed using the GENMOD procedure with log link and Poisson errors in SAS 8.02 (SAS Institute 2000).

In all further analyses, our aim was to disentangle whether the effects of the natural (egg hatching date) and manipulated (photoperiod, food level) larval constraints on adult fitness operated mainly through date of and mass at emergence (emergence traits) or through other, unmeasured variables. Therefore, in contrast to former analyses in which our goal was to determine life history and fitness responses to larval constraints, we used a model selection approach. We compared models using Akaike's Information Criterion, AIC (Burnham and Anderson 1998). AIC rewards better model fit (as measured by the log-likelihood, $L$ ) while penalizing for the number of parameters $(K)$ : AIC $=$ $-2 L+2 K$. Smaller AIC values indicate better models. We first made a list of a priori candidate models, which were then ranked using AIC. For comparing alternative models, we rescaled AIC values such that the model with the minimum AIC has a value of zero. The resulting values, $\triangle \mathrm{AIC}$, are interpreted using the rule of thumb that if $\triangle \mathrm{AIC}<2$, then models have approximately equal support. If $\Delta \mathrm{AIC}>2$, then the model with the lowest AIC has considerably more support from the data. The strength of support for each model was also evaluated using Akaike weights $\left(w_{i}\right)$ (Burnham and Anderson 1998). Akaike weights estimate the relative frequency with which a model would be best supported out of the set of a priori models if the experiment were repeated a large number of times. For example, a model with $w_{i}=0.60$ is three times as likely as a model with $w_{i}=0.20$.

We considered six competing models reflecting the hypotheses that we wanted to test (see Introduction and Table 1). All models included family and sex. Interactions with sex were included in some models to specifically evaluate our prediction that fitness effects of life history responses to larval constraints were sex 
specific. Models 1 and 2 included the larval constraints and their interactions with sex, respectively. Models 3-5 included the emergence traits, their interactions with sex, and also their quadratic terms and interaction, respectively. Model 5 was included because stabilizing selection may be expected for timing of and mass at emergence (Fincke 1988, Anholt 1991, Stoks 2000). Because age at emergence and emergence date were highly correlated and emergence date is a more relevant variable when examining the adult stage, we only included the latter in the model. Similarly, because growth rate and mass at emergence were correlated, only mass at emergence was included in the models. Finally, model 6 combined all the variables of the best model with only larval constraints and the best model with only emergence traits.

If a model with only larval constraints (models 12) gives the best fit, this indicates that larval constraints explain most of the variation in adult fitness and suggests that larval constraints capture the variation in fitness explained by the two metamorphic traits. Conversely, if a model with only metamorphic traits (models 3-5) gives the best fit, this indicates that these traits explain most of the variation in adult fitness and that these metamorphic traits capture the variation explained by larval constraints. The latter result supports the key assumption of optimality models. Finally, if the combined model (model 6) gives the best fit, this indicates that larval constraints and metamorphic traits both have a substantial and unique contribution to the variation in adult fitness. In this case, larval conditions affect adult fitness not only by way of the metamorphic traits, size and timing of emergence, but also via other unmeasured physiological traits. Model fitting was achieved using maximum likelihood with the GENMOD procedure in SAS 8.02 (SAS Institute 2000). For survival to reproductive maturity, we used logit link and binomial errors; for lifetime mating success and mating success after attaining reproductive maturity, we used log link and Poisson errors. In these analyses, egg hatching date and emergence date were $\log _{e}$-transformed to meet model assumptions.

\section{RESUlts}

\section{Larval life history}

A total of 1425 eggs hatched over a period of six weeks (7 April-21 May). Males hatched, on average, three days later than females $\left(F_{1,1271}=68.61, P<\right.$ $0.001)$. Due to an accident during water change, 197 larvae died and only the remaining 1228 animals were included in the analyses. Of these 1228 larvae, 1177 $(95.8 \%)$ adults emerged. Not all adults had fully extended wings and abdomen after emergence; only 902 $(73.5 \%)$ of the larvae emerged successfully. No mass at emergence or growth rate could be determined for the 275 (1177-902) partially emerged individuals.
The probability of successful emergence to adulthood increased with egg hatching date in females. There was no effect of hatching date in males, giving an interaction between hatching date and $\operatorname{sex}\left(\chi_{1}^{2}=\right.$ $3.92, P=0.048$; Fig. 2a, b). The probability of successful emergence was higher when larvae were reared at the actual photoperiod rather than at the delayed photoperiod $\left(\chi_{1}^{2}=31.06, P<0.001\right)$, and when larvae were reared at high food than at low food levels $\left(\chi_{1}^{2}=\right.$ 164.90, $P<0.001$; Fig. 2a, b). Overall, males had a somewhat higher probability of successful emergence than females $\left(\chi_{1}^{2}=3.94, P=0.047\right)$.

A multivariate analysis showed that life history was shaped by all larval constraints: hatching date $\left(F_{1,10}=\right.$ 49.31, $P<0.001)$, photoperiod $\left(F_{1,10}=27.25, P<\right.$ $0.001)$, and food level $\left(F_{1,10}=16.69, P=0.0022\right)$. Larval life history differed between sexes $\left(F_{1,10}=\right.$ 91.77, $P<0.001)$. Moreover, there were significant interactions between hatching date and photoperiod $\left(F_{1,10}=25.31, P<0.001\right)$, between hatching date and food level $\left(F_{1,10}=20.93, P=0.0010\right)$, and between sex and food level $\left(F_{1,10}=13.71, P=0.0041\right)$ on life history. We report these effects in detail for each life history variable separately.

Larvae from eggs that hatched later in the season had a higher development rate than larvae from eggs that hatched earlier in the season $\left(F_{1,736}=341.61, P\right.$ $<0.001)$, as indicated by their lower age at emergence. This was somewhat more pronounced at high food levels, giving a two-way interaction between hatching date and food level $\left(F_{1,1161}=11.74, P<0.001\right.$; Fig. 2 c, d $)$. Age at emergence was lower in larvae reared at the delayed than at the actual photoperiod $\left(F_{1,1161}=\right.$ 656.96, $P<0.001)$ and at high than at low food levels $\left(F_{1,1161}=6.69, P=0.0098\right.$; Fig. $\left.2 \mathrm{c}, \mathrm{d}\right)$. Males emerged, on average, two days before females $\left(F_{1,1166}=25.22\right.$, $P<0.001)$.

Larvae from eggs that hatched later had a higher growth rate than larvae from eggs that hatched earlier $\left(F_{1,397}=408.81, P<0.001\right)$. This effect of hatching date interacted with photoperiod (hatching date $\times$ photoperiod: $\left.F_{1,887}=26.65, P<0.001\right)$ and food level (hatching date $\times$ food level: $F_{1,890}=44.88, P<0.001$; Fig. 2e, f). Although growth rates were similar at both photoperiods in early-hatched larvae, they were higher at the delayed than at the actual photoperiod in latehatched larvae. Growth rates were higher at high than at low food levels $\left(F_{1,890}=33.62, P<0.001\right)$, and this was more pronounced in late- than in early-hatched larvae. There was no difference in growth rate between sexes $\left(F_{1,893}=0.020, P=0.89\right)$.

Mass at emergence was lower at the delayed than at the actual photoperiod in early-hatched larvae, but similar at both photoperiods in late-hatched larvae (hatching date $\times$ photoperiod: $F_{1,883}=28.08, P<0.001$; Fig. $2 \mathrm{~g}, \mathrm{~h})$. Mass at emergence was higher at high than at low food levels $\left(F_{1,151}=16.78, P<0.001\right)$, and this was more pronounced for late-hatched larvae (hatching 

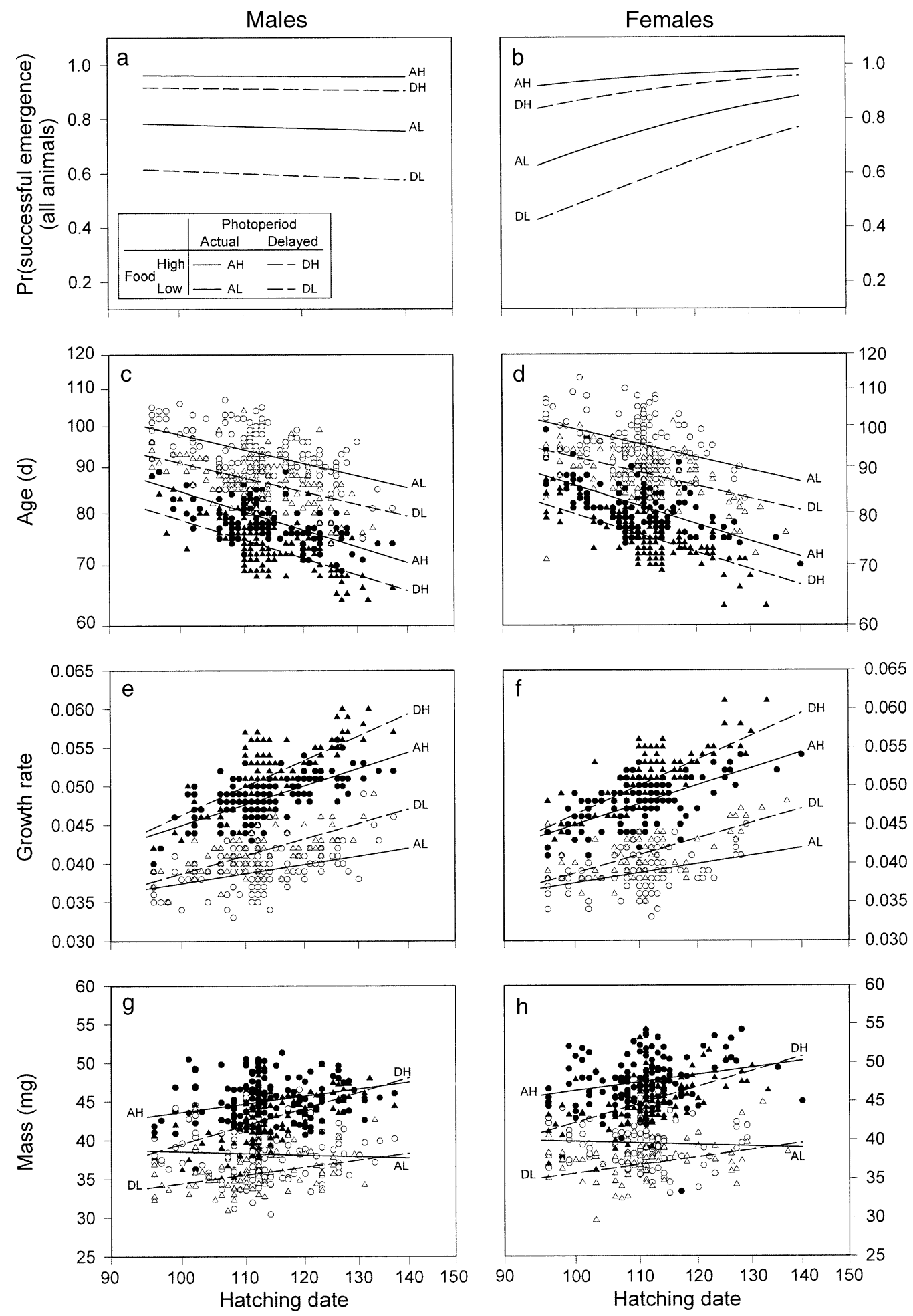

FIG. 2. Metamorphic responses for male and female damselflies: (a, b) the probability of successful emergence, (c, d) age at emergence, $(\mathrm{e}, \mathrm{f})$ growth rate, and $(\mathrm{g}, \mathrm{h})$ mass at emergence in function of hatching date, photoperiod and food level. Before $\log _{e}$-transformation, growth rate was expressed as $\mathrm{mg} / \mathrm{d}$. Regression lines were estimated using the parameter values provided by the respective minimum adequate models. Solid circles show actual photoperiod and high food; open circles show actual photoperiod and low food; solid triangles show delayed photoperiod and high food; open triangles show delayed photoperiod and low food. Day 1 is 1 January 2002. 
date $\times$ food level: $F_{1,150}=21.29, P<0.001$; Fig. $2 \mathrm{~g}$, h). Females were heavier than males, especially at high food levels (food $\times$ sex: $\left.F_{1,889}=14.85, P<0.001\right)$.

\section{Lifetime mating success}

Lifetime mating success of all animals $(n=1228)$ increased with egg hatching date in males but not in females, giving an interaction between hatching date and $\operatorname{sex}\left(\chi_{1}^{2}=20.45, P<0.001\right.$; Fig. 3a, b). Lifetime mating success was higher when larvae were reared at the actual photoperiod than at the delayed photoperiod $\left(\chi_{1}^{2}=33.40, P<0.001\right)$, and when larvae were reared at high food than at low food levels $\left(\chi_{1}^{2}=206.04, P\right.$ $<0.001$; Figs. $3 \mathrm{a}, \mathrm{b}$ and $4 \mathrm{a})$.

Of the 902 adults that emerged successfully, 51 adults were not released in the insectary because of accidental drowning or handling damage when transferring them from the cups and writing a number on their wings. Hence, 851 adults were released in the insectary and only these were included in analyses of the insectary data.

Model selection gave greatest support to model 6 to explain lifetime mating success of these 851 adults (Table 1). All other models had $\triangle \mathrm{AIC}$ values larger than 15. Model 6 included both larval constraints and emergence traits and their interactions with sex. Akaike weights indicated that model 6 is more than 99 times as likely as the second best model, model 2, which included only the larval constraints and their interactions with sex. Therefore, both larval constraints and emergence traits independently contributed in explaining variation in lifetime mating success.

According to model 6, lifetime mating success increased with egg hatching date in males. There was no significant effect of hatching date in females, giving an interaction between hatching date and $\operatorname{sex}\left(\chi_{1}^{2}=\right.$ 21.05, $P<0.001$; Fig. 3c, d). Lifetime mating success was higher for males reared at the actual photoperiod than at the delayed photoperiod $\left(\chi_{1}^{2}=5.24, P=0.022\right)$, but not for females (photoperiod $X$ sex: $\chi_{1}^{2}=5.87, P$ $=0.015$; Figs. $3 \mathrm{c}-\mathrm{h}$ and $4 \mathrm{~b}$ ). Lifetime mating success was also higher when larvae were reared at high food than at low food levels $\left(\chi_{1}^{2}=6.42, P=0.011\right.$; Figs. $3 \mathrm{c}-\mathrm{h}$ and $4 \mathrm{~b})$. There was no effect of emergence date on lifetime mating success $\left(\chi_{1}^{2}=0.02, P=0.88\right.$; Fig. $3 e, f)$. Lifetime mating success increased with mass at emergence in females. There was no significant effect of mass in males, giving an interaction between mass and $\operatorname{sex}\left(\chi_{1}^{2}=4.76, P=0.029\right.$; Fig. $\left.3 \mathrm{~g}, \mathrm{~h}\right)$. Lifetime mating success did not differ between sexes $\left(\chi_{1}^{2}=0.12\right.$, $P=0.73)$.

\section{Survival to reproductive maturity}

Of the 446 males and 405 females that were released in the insectary, $147(33.0 \%)$ and 115 (28.4\%), respectively, survived until reproductive maturity. Model 2 , which included larval constraints and their interactions with sex, was the best supported overall model (lowest AIC) to explain variation in survival to maturity. Model 2 differed only slightly from model 6 $(\Delta \mathrm{AIC}=1.30 ;$ Table 1$)$, which also included the emergence traits and their interactions with sex. However, model 2 was more parsimonious and the Akaike weights $\left(w_{i}\right)$ indicated that model 2 is 3.7 times as likely as model 6. Models only including emergence traits had no support $\left(\Delta \mathrm{AIC}>14, w_{i}<0.001\right.$; Table 1$)$, indicating that variation in survival explained by the emergence traits is completely included in variation explained by the larval constraints.

According to model 2, survival to reproductive maturity increased with egg hatching date in males. There was no effect of hatching date in females, giving an interaction between hatching date and sex $\left(\chi_{1}^{2}=8.07\right.$, $P=0.0045$; Fig. 5a, b). Survival was higher when larvae were reared at the actual photoperiod than at the delayed photoperiod $\left(\chi_{1}^{2}=4.99, P=0.025\right.$; Fig. 5a, b). Survival was also higher when larvae were reared at high food than at low food levels $\left(\chi_{1}^{2}=44.36, P<\right.$ 0.001 ), especially in females (food $\times$ sex: $\chi_{1}^{2}=6.03$, $P=0.014$; Fig. 5a, b). Overall, males had a somewhat higher probability of surviving until reproductive maturity than females $\left(\chi_{1}^{2}=7.88, P=0.0050\right)$.

\section{Mating success after attaining reproductive maturity}

Mating success for damselflies that survived to reproductive maturity was $1.5 \pm 0.1$ (mean $\pm 1 \mathrm{SE}$; variance 2.2) for males and $1.9 \pm 0.2$ (variance 3.8) for females. Model selection gave greatest support to model 6, which included both larval constraints and emergence traits and their interactions with sex. All other models received $\Delta$ AIC values larger than 4 (Table 1). Akaike weights indicated that model 6 is 61.5 times as likely as the second best model, model 2, which included only the larval constraints and their interactions with sex. Therefore, both larval constraints and emergence traits independently contributed in explaining variation in mating success for those animals that attained reproductive maturity.

Both manipulated larval constraints included in model 6 only affected mating success in males (for photoperiod $\times \operatorname{sex}, \chi_{1}^{2}=3.66, P=0.055$; for food $\times$ sex, $\chi_{1}^{2}=11.04, P<0.001$; Figs. $4 \mathrm{c}$ and $5 \mathrm{c}-\mathrm{h}$ ). Male mating success was higher when larvae were reared at the actual photoperiod than at the delayed photoperiod and at high food than at low food levels. There was no effect of hatching date and emergence date on mating success (both $P>0.37$; Fig. 5c-f). Overall, damselflies with a higher mass at emergence had a higher mating success $\left(\chi_{1}^{2}=7.58, P=0.0059\right)$. This effect was more pronounced in females $\left(\right.$ sex $\times$ mass: $\chi_{1}^{2}=3.83, P=$ 0.050; Fig. 5g, h).

\section{Discussion}

\section{Larval constraints and emergence traits}

Both time and nutritional constraints affected the probability of successful emergence and emergence 

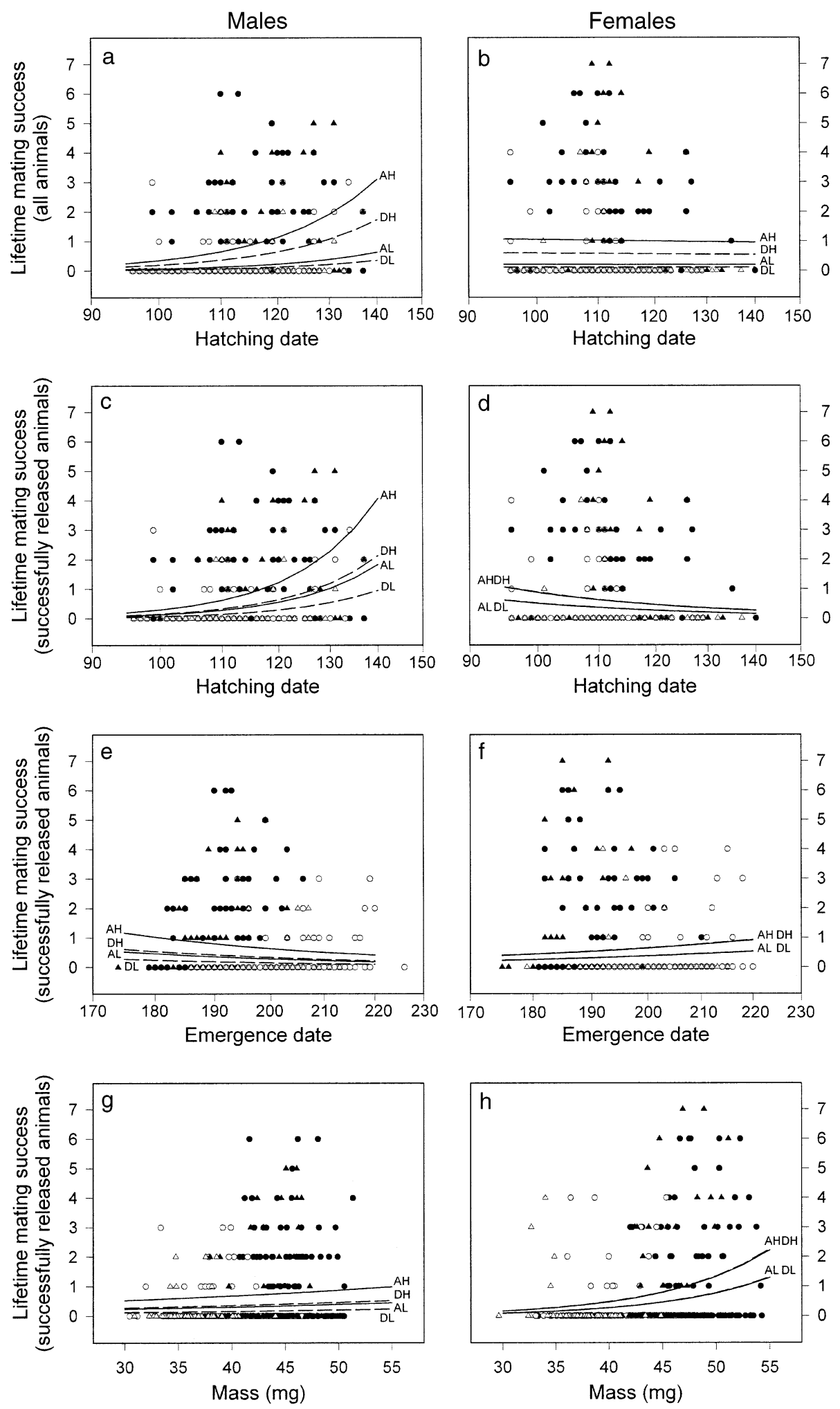

FIG. 3. (a, b) Sex-specific lifetime mating success for all damselflies $(n=1228)$ plotted against hatching date. (c-h) Sexspecific lifetime mating success for all damselflies that were released in the insectary $(n=851)$ plotted against (c, d) hatching date, $(e, f)$ emergence date, and $(g, h)$ mass at emergence for each combination of photoperiod and food level. Regression lines were estimated using the parameter values provided by the respective minimum adequate model (a, b), and model 6 of Table $1(\mathrm{c}-\mathrm{h})$. Symbols are as in Fig. 2; Day 1 is 1 January 2002. 

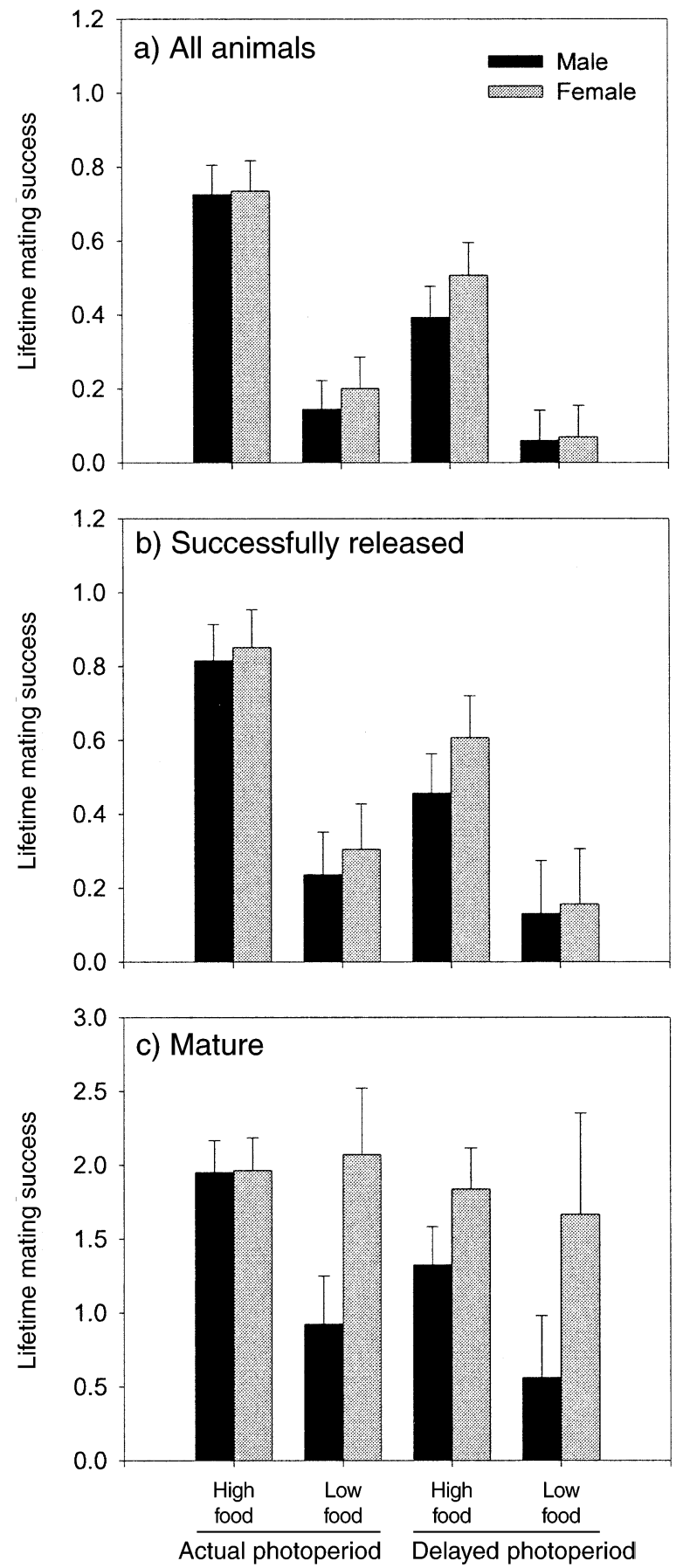

FIG. 4. Lifetime mating success (mean $\pm 1 \mathrm{SE}$ ) for (a) all damselflies $(n=1228)$, (b) all damselflies that were released in the insectary $(n=851)$, and (c) damselflies that survived until reproductive maturity $(n=262)$ for each combination of photoperiod, food level, and sex.

traits. Food shortage and time constraints imposed by a late photoperiod reduced the chance of successful emergence. This is probably due to reduced energy reserves. The effects on size and timing of emergence were largely in agreement with predictions of opti- mality models (reviewed in Day and Rowe 2002). Under both the natural and manipulated time constraint, larvae accelerated their development. With increasing natural time constraints (egg hatching date), larvae showed higher growth rates. Under the manipulated time constraint (photoperiod), only larvae that hatched late in the season increased their growth rate. As a result, these late-hatched larvae compensated for the shorter development time so that their mass at emergence was not affected, whereas early-hatched larvae emerged at a smaller mass. Larvae reared at the high food level accelerated development and had a higher mass at emergence, which was associated with a higher growth rate relative to larvae reared at a lower food level. These life history responses to food level were more pronounced in late-hatched larvae.

Egg hatching date determined how size and timing of emergence were influenced by the manipulated time and nutritional constraints. Egg hatching date has largely been ignored in empirical (but see Altwegg 2002) and theoretical work, but may explain some inconsistencies between empirical tests of optimality models. It is unclear at this point what underlies these effects of hatching date. Temperature and food were kept constant, and further advanced photoperiods are an unlikely environmental source. For example, earlyhatched larvae at the delayed photoperiod experienced a more advanced photoperiod than late-hatched larvae at the actual photoperiod, despite the higher growth rate of the latter. The presence of these effects within our full-sib families suggests that maternal effects may have been responsible (Bertram and Strathmann 1998).

\section{Linking larval constraints to adult fitness}

Based on all animals, including those that did not emerge successfully, we demonstrated that the manipulated larval constraints negatively influenced fitness as measured by lifetime mating success. To our knowledge, this is the first study that has directly studied the effect of manipulated time constraints on lifetime mating success, and therefore the first evidence that time constraints may truly decrease an animal's fitness, despite compensatory development and growth mechanisms. Moreover, by focusing only on those animals that emerged successfully, we showed that the fitness effects induced by time and nutritional constraints in the larval stage were not completely mediated through the emergence traits and were often sex specific.

Larval constraints and mass at emergence independently explained variation in lifetime mating success. The manipulated time constraint and the nutritional constraint reduced lifetime mating success. Later egg hatching dates, on the contrary, increased lifetime mating success in males but not in females. Females, however, had a higher lifetime mating success when they had a higher mass at emergence. We next discuss these effects in more detail for each fitness component, sur- 

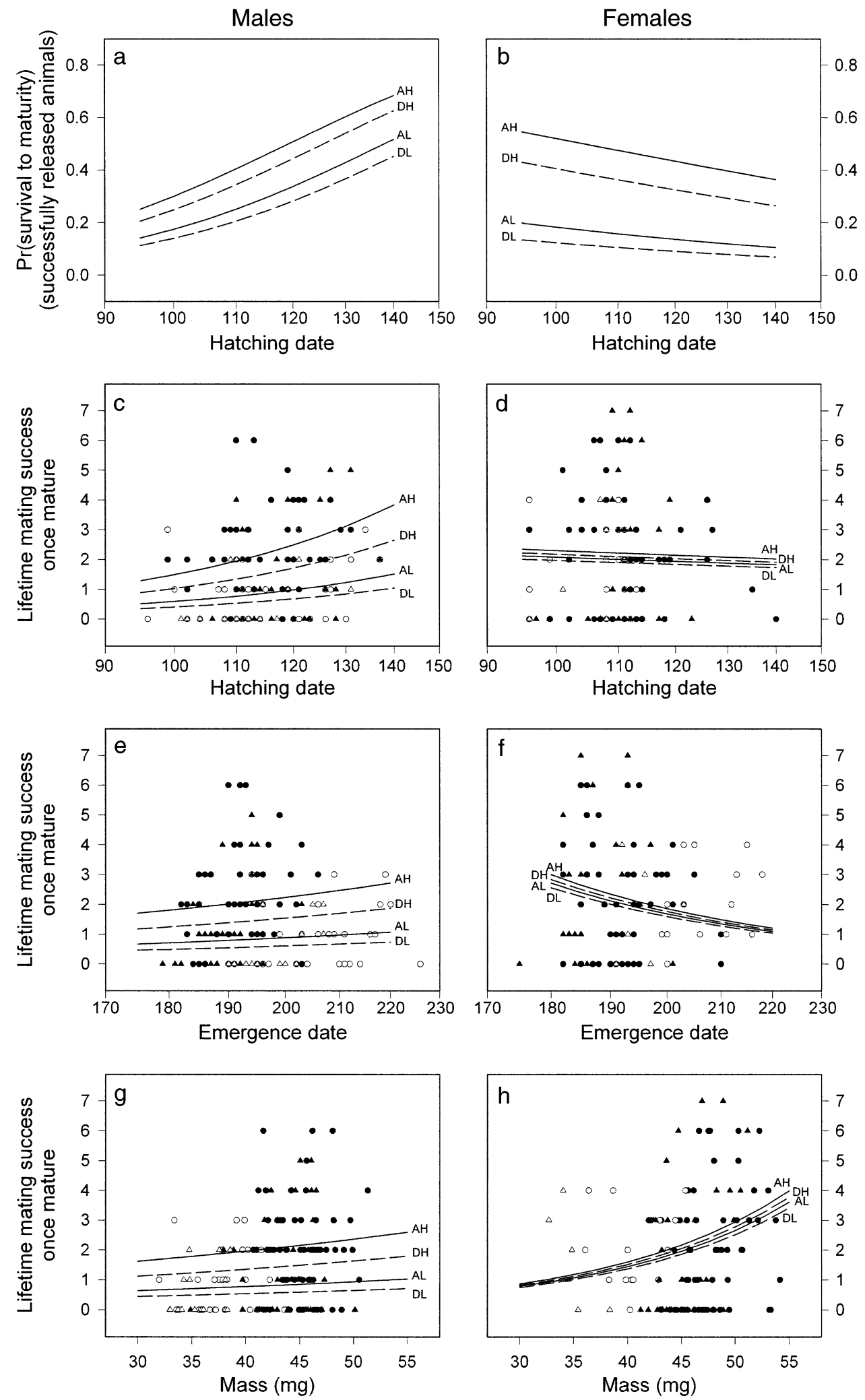

FIG. 5. (a, b) Sex-specific survival to reproductive maturity $(n=851)$ plotted against hatching date. $(\mathrm{c}-\mathrm{h})$ Lifetime mating success for damselflies that survived to reproductive maturity $(n=262)$ plotted against $(c, d)$ hatching date, $(e, f)$ emergence date, and $(\mathrm{g}, \mathrm{h})$ mass at emergence. Results are presented for each combination of photoperiod and food level. Regression lines were estimated using the parameter values provided by model 2 for survival to maturity and by model 6 for mating success once mature (Table 1). Symbols are as in Fig. 2; Day 1 is 1 January 2002. 
vival to reproductive maturity, and mating success after attaining reproductive maturity.

Larval constraints explained more variation in survival to reproductive maturity than did mass and timing of emergence. Survival was reduced under both the manipulated time constraint (late photoperiod) and the nutritional constraint. Under these constraints, larvae not only emerged at a smaller mass but also probably had reduced energy reserves independent of their smaller mass, and these may be more tightly linked to survival than mass itself. This is supported by the fact that under a manipulated time constraint Lestes sponsa allocated more ingested food to mass and less to other functions (R. Stoks, M. De Block, F. Van de Meutter, and F. Johansson, unpublished manuscript). Additional support for a smaller investment in storage molecules comes from studies showing reduced starvation resistance in animals under a time constraint (reviewed in Gotthard 2001). Under a nutritional constraint, a reduced investment in storage molecules such as fat, independent of mass reduction, has been shown in Lestes viridis (Rolff et al. 2004), other damselflies (Plaistow and Siva-Jothy 1999), and other taxa (e.g., Phillips 2002). The nutritional constraint reduced survival to maturity more in females than in males. This may be explained by the fact that mass increase during the prereproductive period is much larger in female than in male Lestes, and is associated with more risky foraging (Stoks 2001). These sex differences are probably much more pronounced when animals emerge with less energy content. In contrast with the manipulated time constraint, survival to reproductive maturity increased with later egg hatching dates in males, but not in females. This effect of egg hatching date cannot completely be explained through emergence date and we have no explanation for it.

Variation in mating success after attaining reproductive maturity was shaped by mass at emergence, especially in females, and by manipulated larval constraints in males. Animals had a higher mating success when they had a higher mass at emergence, and this was not purely due to larval constraints. A positive relationship between body size or mass and lifetime mating success has been found generally in damselflies (reviewed in Sokolovska et al. [2000], but see Thompson and Fincke [2002]). When reared under a manipulated time or nutritional constraint, males had not only a lower survival to reproductive maturity, but also a lower lifetime mating success. This effect could not be explained simply by their emergence traits. This longlasting effect of larval constraints in males is intriguing and suggests that the previously mentioned energetic costs due to these constraints may persist throughout their reproductive life. In scrambling species like Lestes, males with higher energy reserves may spend more time searching for females and therefore may have a higher mating success (Anholt 1991, Stoks 1999). In contrast, receptive females can obtain matings without search costs, due to the highly male-biased operational sex ratios (Stoks 1999). Such long-lasting effects of larval constraints on adult fitness, which do not operate through emergence traits, are problematic for studies on lifetime mating success. Studies on lifetime mating success mostly only consider typical fitness correlates such as size and typically have no knowledge of prior history of the larval stage. Our results suggest that ignoring the larval history may cause the often large part of unexplained variation in selection studies (Clutton-Brock 1988, Choe and Crespi 1997, Thompson and Fincke 2002).

Our results show that the two life history variables typically included in optimality models (e.g., Rowe and Ludwig 1991, Abrams et al. 1996), size and timing of the life history transition, cannot completely account for effects of time and nutritional constraints on fitness. Therefore, our study indicates that the predictive value of traits such as age and size at maturity might be restricted. This does not necessarily imply that age and size are not optimized and linked to fitness. For example, timing of emergence is crucial in this species, which often occupies temporary ponds that dry up early in summer (in dry years, entire populations are wiped out this way; M. De Block and R. Stoks, personal observation). Instead, our results indicate that larvae may be optimizing not only these life history variables but also other unmeasured ones. These unmeasured variables are very likely independent targets of selection, even potentially traded off against each other. Current life history optimality models are only valid when larval constraints are completely captured by age and size at maturity. Therefore, our results strongly suggest that identifying variables that are under more direct selection and including them in optimality models is of primary importance to better understand and predict fitness effects of larval constraints and the evolution of life history plasticity in response to constraints.

Some previous studies explicitly exploring the link between larval constraints and adult fitness showed that effects of larval constraints on survival (Altwegg and Reyer 2003), and on survival and mating success after attaining reproductive maturity (Anholt 1991), could be explained completely through size and timing of the life history transition. However, two other types of studies concur, although indirectly, with our finding that carryover effects of larval constraints on adult fitness do not operate solely through size and timing of transition. One group of studies is linked with compensatory growth after food shortage in the larval stage. Larvae that suffered a period of food shortage can show accelerated growth when conditions improve, and may become virtually indistinguishable at transition from those reared without food shortage. However, this comes at a variety of costs that often are not evident until much later in adult life (reviewed in Metcalfe and Monaghan 2001). A second group of studies is associated with predator-induced phenotypic plasticity. For 
example, Benard and Fordyce (2003) showed that larval western toads, Bufo boreas, reared in the presence and absence of predator cues did not differ in metamorphic traits, but those reared under predator stress had a reduced postmetamorphic chemical defense. Such studies indicate that costs of larval constraints are not always captured by traditionally measured metamorphic traits, but can instead remain hidden until a later point when they translate into easily detected variables such as mortality rate and mating success.

Taken together, age and size at emergence do not appear to completely bridge the gap between larval constraints and adult fitness, which may partly invalidate using only these end points in empirical studies that test optimality models. Our results also urge caution when manipulating ecological factors to expand phenotypic variances to increase the power of selection studies, because the manipulation itself may cause carryover effects not covered by the phenotypic variables under study (Travis and Reznick 1998). These ecological factors should be included in the selection studies to evaluate whether the manipulation has effects on other unmeasured variables (see Anholt 1991, Altwegg and Reyer 2003). Studies extending the set of typical fitness correlates may provide better refined insights on the coupling between larval and adult stages and therefore on the evolution of complex life cycles and the direct targets of natural and sexual selection. More generally, further progress on understanding life history transitions may benefit from empirical studies focusing not only on the predictions but also on the largely neglected underlying assumptions of the models.

\section{ACKNOWLEDGMENTS}

We are grateful to Res Altwegg, Thierry Backeljau, Melina Campero-Paz, Stephen Davis, Mark McPeek, Jens Rolff, Lock Rowe, Andrew Sih, Stefan Van Dongen, and an anonymous referee whose comments greatly improved the paper. Many thanks to Frans De Block and Simonne Vandenbroeck for their help with the construction of the mating cages and insectary. M. De Block is funded by a grant from the Flemish Institute for the Promotion of Innovation by Science and Technology (IWT). R. Stoks benefited from a postdoctoral fellowship and research grants of the Fund for Scientific Research Flanders (FWO).

\section{Literature Cited}

Abrams, P. A., O. Leimar, S. Nylin, and C. Wiklund. 1996. The effect of flexible growth rates on optimal sizes and development times in a seasonal environment. American Naturalist 147:381-395.

Altwegg, R. 2002. Predator-induced life-history plasticity under time constraints in pool frogs. Ecology 83:25422551.

Altwegg, R., and H.-U. Reyer. 2003. Patterns of natural selection on size at metamorphosis in water frogs. Evolution 57:872-882.

Andersson, M. 1994. Sexual selection. Princeton University Press, Princeton, New Jersey, USA.

Anholt, B. R. 1990. Size-biased dispersal prior to breeding in a damselfly. Oecologia 83:385-387.

Anholt, B. R. 1991. Measuring selection on a population of damselflies with a manipulated phenotype. Evolution 45: 1091-1106.
Benard, M. F., and J. A. Fordyce. 2003. Are induced defenses costly? Consequences of predator-induced defenses in western toads, Bufo boreas. Ecology 84:68-78.

Bertram, D. F., and R. R. Strathmann. 1998. Effects of maternal and larval nutrition on growth and form of planktotrophic larvae. Ecology 79:315-327.

Burnham, K. P., and D. R. Anderson. 1998. Model selection and inference: a practical information-theoretic approach. Springer-Verlag, New York, New York, USA.

Choe, J. C., and B. J. Crespi. 1997. Mating systems in insects and arachnids. Cambridge University Press, Cambridge, UK.

Clutton-Brock, T. H. 1988. Reproductive success. University of Chicago Press, Chicago, Illinois, USA.

Crawley, M. J. 1993. GLIM for ecologists. Blackwell Scientific Publications, Oxford, UK.

Crawley, M. J. 2002. Statistical computing. John Wiley, Chichester, UK.

Crowley, P. H. 2000. Sexual dimorphism with female demographic dominance: age, size, and sex ratio at maturation. Ecology 81:2592-2605.

Crowley, P. H., and F. Johansson. 2002. Sexual dimorphism in Odonata: age, size, and sex ratio at emergence. Oikos 96:364-378

Day, T., and L. Rowe. 2002. Developmental thresholds and the evolution of reaction norms for age and size at lifehistory transitions. American Naturalist 159:338-350.

De Block, M., and R. Stoks. 2003. Adaptive sex-specific life history plasticity to temperature and photoperiod in a damselfly. Journal of Evolutionary Biology 16:986-995.

De Block, M., and R. Stoks. 2004. Life-history variation in relation to time constraints in a damselfly. Oecologia 140: 68-75.

Fincke, O. M. 1988. Sources of variation in lifetime reproductive success in a non-territorial damselfly (Odonata: Coenagrionidae). Pages 24-43 in T. H. Clutton-Brock, editor. Reproductive success. University of Chicago Press, Chicago, Illinois, USA.

Gotthard, K. 2001. Growth strategies of ectothermic animals in temperate environments. Pages 287-303 in D. Atkinson and $\mathrm{M}$. Thorndyke, editors. Environment and animal development: genes, life histories and plasticity. BIOS, Oxford, UK.

Honĕk, A. 1993. Intraspecific variation in body size and fecundity in insects: a general relationship. Oikos 66:483492.

Jödicke, R. 1997. Die Binsenjungfern und Winterlibellen Europas. Westarp, Magdeburg, Germany.

Johansson, F., and L. Rowe. 1999. Life history theory and behavioral responses to time constraints in a damselfly. Ecology 80:1242-1252.

Johansson, F., R. Stoks, L. Rowe, and M. De Block. 2001. Life history plasticity in a damselfly: effects of combined time and biotic constraints. Ecology 82:1857-1869.

Littell, R. C., G. A. Milliken, W. W. Stroup, and R. D. Wolfinger. 1996. SAS system for mixed models. SAS Institute, Cary, North Carolina, USA.

Metcalfe, N. B., and P. Monaghan. 2001. Compensation for a bad start: grow now, pay later? Trends in Ecology and Evolution 16:254-260.

Moran, N. A. 1994. Adaptation and constraint in the complex life cycle of animals. Annual Review of Ecology and Systematics 25:573-600.

Morey, S., and D. Reznick. 2001. Effects of larval density on postmetamorphic spadefoot toads (Spea hammondii). Ecology 82:510-522.

Nylin, S., and K. Gothard. 1998. Plasticity in life-history traits. Annual Review of Entomology 43:63-83.

Phillips, N. E. 2002. Effects of nutritional-mediated larval conditions on juvenile performance in a marine mussel. Ecology 83:2562-2574. 
Pickup, J., D. J. Thompson, and J. H. Lawton. 1984. The life history of Lestes sponsa (Hansemann): larval growth (Zygoptera: Lestidae). Odonatologica 13:451-459.

Plaistow, S., and M. T. Siva-Jothy. 1996. Energetic constraints and male mate-securing tactics in the damselfly Calopteryx splendens xanthostoma (Charpentier). Proceedings of the Royal Society of London B 263:1233-1239.

Plaistow, S., and M. T. Siva-Jothy. 1999. The ontogenetic switch between odonate life history stages: effects on fitness when time and food are limited. Animal Behaviour 58:659-667.

Roff, D. A. 1986. Predicting body size with life history models. BioScience 36:316-323.

Rolff, J., F. Van de Meutter, and R. Stoks. 2004. Time constraints decouple age and size at maturity and physiological traits. American Naturalist 164:559-565.

Rowe, L., and D. Ludwig. 1991. Size and timing of metamorphosis in complex life cycles: time constraints and variation. Ecology 72:413-427.

SAS Institute. 2000. SAS/STAT user's guide. Version 8. SAS Institute, Cary, North Carolina, USA.
Sokolovska, N., L. Rowe, and F. Johansson. 2000. Fitness and body size in mature odonates. Ecological Entomology 25:239-248.

Stoks, R. 1999. Natural and sexual selection in the damselfly Lestes sponsa. Dissertation. University of Antwerp, Antwerp, Belgium.

Stoks, R. 2000. Components of lifetime mating success and body size in males of a scrambling damselfly. Animal Behaviour 59:339-348.

Stoks, R. 2001. What causes male-biased sex ratios in mature damselfly populations? Ecological Entomology 26:188197.

Thompson, D. J., and O. M. Fincke. 2002. Body size and fitness in Odonata, stabilising selection and a meta-analysis too far? Ecological Entomology 27:378-384.

Travis, J., and D. N. Reznick. 1998. Experimental approaches to the study of evolution. Pages 437-459 in W. J. Resetarits and J. Bernardo, editors. Experimental ecology. Oxford University Press, New York, New York, USA.

Verbeke, G., and G. Molenberghs. 1997. Linear mixed models in practice: a SAS-oriented approach. Springer-Verlag, New York, New York, USA. 